\title{
Strangulated Transanal Evisceration of Small Bowel Complicating Rectal Prolapse of the Child: An Observation of the University Hospital Center of Parakou, Benin
}

\author{
Montcho Adrien Hodonou*, Bio Tamou-Sambo, Isidore Gandaho, Djifid Morel Séto, \\ Salako Alexandre Allode \\ Department of General Surgery, School Hospital of Parakou, Faculty of Medicine, University of Parakou, Parakou, Benin \\ Email: *hodasm98@gmail.com
}

How to cite this paper: Hodonou, M.A., Tamou-Sambo, B., Gandoho, I., Séto, D.M. and Allode, S.A. (2018) Strangulated Transanal Evisceration of Small Bowel Complicating Rectal Prolapse of the Child: An Observation of the University Hospital Center of Parakou, Benin. Surgical Science, 9, 85-89.

https://doi.org/10.4236/ss.2018.92008

Received: January 29, 2018

Accepted: February 10, 2018

Published: February 13, 2018

Copyright $\odot 2018$ by authors and Scientific Research Publishing Inc. This work is licensed under the Creative Commons Attribution International License (CC BY 4.0).

http://creativecommons.org/licenses/by/4.0/

\begin{abstract}
Transanal intestinal evisceration is an extremely rare and dramatic digestive surgical emergency. The cases reported in the literature are few and concern much more elderly patients. We report the case of a 3-year-old boy admitted in very general poor condition to the emergency department, late for transanal evisceration complicating rectal prolapse that the parents tried to reduce. The fatal outcome of this case is probably related to strangulation and delay in consultation. We learn from this that parents should avoid inopportune prolapse reduction and early consultation.
\end{abstract}

Keywords

Transanal Evisceration, Strangulation, Rectal Prolapse, Child, Benin

\section{Introduction}

Transanal evisceration of the small bowel is very rare [1]. The first description was made in 1827 by Benjamin Brodie [2]. Since this time, few cases mostly encountered in adults were described. This is surgical emergency due to herniation of bowel through breach in the rectal wall and seen eviscerating through the anus. We report a case of transanal evisceration with strangulation of the small bowel in a child. Through this observation, we propose to discuss the aetiological and therapeutic possibilities.

\section{Case Report}

It was a 3-year-old boy referred to Parakou University Hospital for the exteri- 
orization of small loops through the anus. Interrogation found: late admission of 17 hours, dysentery about 4 days and a history of rectal protrusion during defecation one year of age, without another pathologic antecedent. This was usually reduced by the parents. The evisceration occurred during the last attempt of manual reduction. Physical examination showed pale conjunctiva and mucous membranes, a pulse rate of 96 beats per minute and a respiratory rate of 26 cycles per minute. Perineal examination noted an evisceration such as a voluminous intestinal pelvic mass spiral, strangulated and inflammatory under pressure (Figure 1). The abdomen was slightly enlarged, not very depressible but sensitive. Digital rectal examination was impossible. Transanal evisceration with strangulated small bowel through rectal prolapse is concluded. Biological assessment showed severe anemia at $6.7 \mathrm{~g} / \mathrm{dl}$ and hyponatremia at $130 \mathrm{mmol} / \mathrm{l}$. The eviscerated loops were covered with wet and saline compresses. A medical resuscitation was instituted promptly (introduction of a gastric tube that brings greenish liquid, analgesic, antibiotic and blood transfusion) with the preoperative assessment. Unfortunately, the patient died during this preoperative phase two hours after admission, parents refused examination after death.

\section{Discussion}

\subsection{Epidemiological Aspects}

Transanal evisceration of the small intestine is a rare pathological condition [3] [4]. Bâ PA et al. describes it as spectacular [3]. This is a well-known phenomenon in adult subjects [4] where most reported cases were associated with rectal prolapse [1] [2]. The aetiological circumstances are rather varied in the pediatric population. We thus find cases of abdominal trauma [5] [6], trauma by impaction [7] [8], aspiration accident on pool bung [4] [9]. Another etiology is sexual abuse in a girl child reported by Press S et al. in 1991 [10]. In our patient, evisceration is a complication of rectal prolapse as it occurred during the reduction attempt.

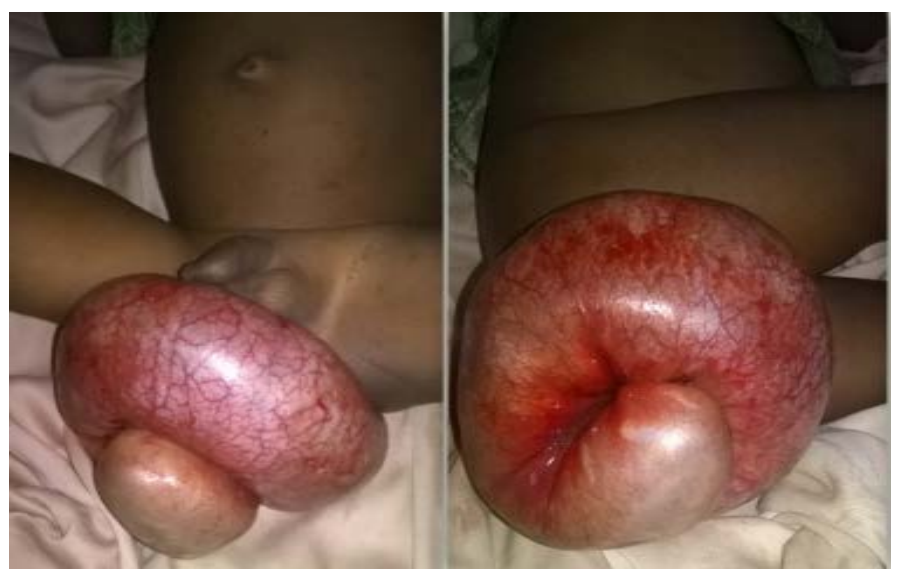

(a)

(b)

Figure 1. Small bowel loop, eviscerated and strangulated through the anus. (a) supine patient, (b) patient in left lateral decubitus. 


\subsection{Pathogenic Aspects}

With regard to rectal prolapse, all authors agree on the mechanism of spontaneous perforation of the rectum [1] [4] [11] [12]. Factors of abdominal hyperpressure such as exoneration, vomiting, cough can lead to the perforation. In our observation, this hyperpressure is caused by the attempt to reduce the prolapse manually as Trinidade A et al. Case [1]. These latters justify that in this position, the gravitational weight of the small intestinal mass against the rectal wall makes it technically more difficult to reduce and forces to use more manual force resulting in the sudden increase in intra-abdominal pressure. The consequence is rupture of rectal wall followed immediately by evisceration of the small intestine. The gap usually sits on the anterior surface of the rectum near the peritoneal reflection [3] and may be transverse [12] or longitudinal [13]. Petras et al. [14] demonstrated clearly an aetiopathogenic link between focal rectal ischemia and perforation. Since the small intestine has prolapsed through a more or less narrow rectal gap, it can be strangulated with tonic anal sphincter [1]. This was surely the case of our patient given the notion of dysentery syndrome.

\subsection{Diagnostic Aspects}

Although the diagnosis of this condition is mainly clinical, imaging can play a role in its management. A X-ray of the abdomen without preparation can detect peritoneal and retroperitoneal emphysema [15]. In addition, computed tomography may be useful for detecting presence of air outside the rectosigmoid junction. This suggests a parietal rupture and may help plan a surgical procedure [15].

\subsection{Therapeutic Aspects and Prognosis}

Appropriate resuscitation and rapid surgery are the mainstays of treatment [1]. The eviscerated intestine should be cleaned with saline and gently reduced in the peritoneal cavity with simultaneous support and guidance through the anal canal. But most of the time this attempt at reduction without laparotomy proves to be fruitless [16] as mentioned by several case studies [3] [11]. We did not attempt it in our patient because of the strangulation and inflammation of the loop. Perineal surgery was planned in order to perform a recto-sigmoid resection followed by a colo-anal anastomosis (Intervention of Altemeier) but given the precarious state of health of the child (ASA 5): severe anemia, poor general condition, hydro-ionic disorders, a two-stage intervention would be more lawful. The first step would be to remove the urgency by reducing evisceration and treating lesions of the small bowel (resection and ileostomy in case of necrosis); in the second deferred time, we would take care to treat the rectal prolapse. In adults, laparotomy is followed by bowel resection with immediate anastomosis followed [14] by suturing of the rectal gap that may or may not be protected by a temporary colostomy. The definitive repair of rectal prolapse by rectopexy or by intervention of Altemeier can be considered in eligible candidates [1]. 
Trans-anal evisceration of the small intestine shows high mortality [13]. The review of literature by Morris et al. [17] revealed 53 cases of evisceration of the small bowel on rectal prolapse since the first case described by Brodie and of these 53 cases, $22(41.5 \%)$ cases had died. Our patient died in the preoperative phase after a short delay after admission, as reported by Berwin JT et al. [16].

\section{Conclusion}

Children with rectal prolapse have a real risk of evisceration, especially when parents are attempting untimely maneuvers for reduction. To our knowledge, this observation is the first in the scientific literature of Benin. A senbilisation of the parents is necessary for a rapid consultation in case of rectal prolapse whose usual maneuvers do not make it possible to reduce.

\section{References}

[1] Trinidade, A., Shakeel, M. and Transanal, J.S. (2010) Small Bowel Evisceration Following Digital Reduction of a Chronically Prolapsing Rectum. Journal of the College of Physicians and Surgeons Pakistan, 20, 760-762.

[2] Kunin, N., Le Roy, M.L., Ollivier, F., Morin-Chouarbi, V. and Verbrackel, L. (2005) Prolapsus rectal avec éviscération transanale aiguë du côlon sigmoïde. Gastroentérologie Clinique et Biologique, 29, 478-479. https://doi.org/10.1016/S0399-8320(05)80824-3

[3] Bâ, P.A., Soumah, S.A., Diop, B., Traoré, M.M., Mahdi, C., Mbaye, E.M., et al. (2011) Eviscération transanale de l'intestin grêle chez l'enfant secondaire à une contusion de l'abdomen: à propos d'un cas. Pan African Medical Journal, 10, 50.

[4] Price, N.R., Soundappan, S.V. and Sparnon, A.L. (2010) Cass DT. Swimming Pool Filter-Induced Transrectal Evisceration in Children: Australian Experience. The Medical Journal of Australia, 192, 534-536.

[5] Rechner, P. and Cogbill, T.H. (2001) Transanal Small Bowel Evisceration from Abdominal Crush Injury: Case Report and Review of the Literature. Journal of Trauma, 50, 934-936. https://doi.org/10.1097/00005373-200105000-00028

[6] Roy, A.K., Shukla, P. and Singh, S. (2009) Rectal Perforation and Evisceration of the Small Intestine: A Rare Injury in Blunt Trauma of the Abdomen. Journal of Trauma, 66, 286. https://doi.org/10.1097/01.ta.0000241170.09288.f9

[7] Bronkhorst, M.W., Wilde, J.C., Hamming, J.F. and Heij, H.A. (2007) Anorectal Impalement in a Pediatric Patient with Transanal Evisceration of Small Bowel. Journal of Pediatric Surgery, 42, 23-25. https://doi.org/10.1016/j.jpedsurg.2007.06.010

[8] Ravikumar, R., Robb, A. and Jawaheer, G. (2008) Small Bowel Evisceration through the Rectum in Childhood. Journal of Pediatric Surgery, 43, 562-563. https://doi.org/10.1016/j.jpedsurg.2007.11.008

[9] Juern, J., Schmeling, D. and Feltis, B. (2010) Transanal Wading Pool Suction-Drain Injury Resulting in Complete Evisceration of the Small Intestine: Case Report and Review of the Literature. Journal of Pediatric Surgery, 45, E1-E3. https://doi.org/10.1016/j.jpedsurg.2010.01.020

[10] Press, S., Grant, P., Thompson, V.T. and Milles, K.L. (1991) Small Bowel Evisceration: Unusual Manifestation of Child Abuse. Pediatrics, 88, 807-809. 
[11] Gomez-Juarez, M., Cascales, P., Garcia-Olmo, D., Gomez-Juarez, F., Usero, S., Capilla, P., et al. (2001) Complete Evisceration of the Small Intestine through a Perianal Wound as a Result of Suction at a Wading Pool. Journal of Trauma, 51, 398-399. https://doi.org/10.1097/00005373-200108000-00033

[12] Nari, G.A., Moreno, E. and Ponce, O. (2001) Transanal Prolapse of the Small Intestine Secondary to Spontaneous Rupture of the Rectum. Annales de Chirurgie, 126, 818-820. https://doi.org/10.1016/S0003-3944(01)00612-5

[13] Corduk, N., Koltuksuz, U., Karabul, M., Savran, B., Bagci, S. and Sarioglu-Buke, A. (2011) A Rare Presentation of Crush Injury: Transanal Small Bowel Evisceration. Case Report and Review of the Literature. Pediatric Surgery International, 27, 1021-1024. https://doi.org/10.1007/s00383-010-2817-9

[14] Prassas, D., Stunneck, D., Rolfs, T.-M. and Schumacher, F.-J. (2017) Transanal Evisceration of the Small Bowel-Report of a Case. Zeitschrift fur Gastroenterologie, 55, 274-276. https://doi.org/10.1055/s-0043-101529

[15] Hovey, M.A. and Metcalf, A.M. (1997) Incarcerated Rectal Prolapsed-Rupture and Ileal Evisceration after Failed Reduction: Report of a Case. Diseases of the Colon and Rectum, 40, 1254-1257. https://doi.org/10.1007/BF02055174

[16] Berwin, J.T., Ho, T.K. and D'Souza, R. (2012) Small Bowel Evisceration through the Anus-Report of a Case and Review of Literature. BMJ Case Reports. https://doi.org/10.1136/bcr.12.2011.5316

[17] Morris, A.M., Setty, S.P., Standage, B.A., et al. (2003) Acute Transanal Evisceration of the Small Bowel: Report of a Case and Review of the Literature. Diseases of the Colon and Rectum, 46, 1280-1283. https://doi.org/10.1007/s10350-004-6727-6 